\title{
$30 S$ ribosomal subunits can be assembled in vivo without primary binding ribosomal protein S15
}

\author{
MIKHAIL BUBUNENKO, ${ }^{1,2}$ ALEXEY KOREPANOV, ${ }^{3}$ DONALD L. COURT, ${ }^{2}$ INDU JAGANNATHAN, ${ }^{4,5}$ \\ DANIEL DICKINSON, ${ }^{4}$ BISWAJOY ROY CHAUDHURI, ${ }^{4}$ MARIA B. GARBER, ${ }^{3}$ and GLORIA M. CULVER \\ ${ }^{1}$ Basic Research Program, SAIC-Frederick, Inc., National Cancer Institute at Frederick, Frederick, Maryland 21702, USA \\ ${ }^{2}$ Molecular Control and Genetics Section, Gene Regulation and Chromosome Biology Laboratory, Center for Cancer Research, \\ National Cancer Institute at Frederick, Frederick, Maryland 21702, USA \\ ${ }^{3}$ Institute of Protein Research, Russian Academy of Sciences, 142290 Pushchino, Moscow Region, Russian Federation \\ ${ }^{4}$ Department of Biochemistry, Biophysics and Molecular Biology, lowa State University, Ames, lowa 50011, USA
}

\begin{abstract}
Assembly of $30 \mathrm{~S}$ ribosomal subunits from Escherichia coli has been dissected in detail using an in vitro system. Such studies have allowed characterization of the role for ribosomal protein S15 in the hierarchical assembly of 30S subunits; S15 is a primary binding protein that orchestrates the assembly of ribosomal proteins S6, S11, S18, and S21 with the central domain of 16S ribosomal RNA to form the platform of the $30 \mathrm{~S}$ subunit. In vitro S15 is the sole primary binding protein in this cascade, performing a critical role during assembly of these four proteins. To investigate the role of S15 in vivo, the essential nature of $r p s O$, the gene encoding S15, was examined. Surprisingly, $E$. coli with an in-frame deletion of $r p s O$ are viable, although at $37^{\circ} \mathrm{C}$ this $\Delta r p s O$ strain has an exaggerated doubling time compared to its parental strain. In the absence of S15, the remaining four platform proteins are assembled into ribosomes in vivo, and the overall architecture of the $30 \mathrm{~S}$ subunits formed in the $\Delta$ rps $O$ strain at $37^{\circ} \mathrm{C}$ is not altered. Nonetheless, 30S subunits lacking S15 appear to be somewhat defective in subunit association in vivo and in vitro. In addition, this strain is cold sensitive, displaying a marked ribosome biogenesis defect at low temperature, suggesting that under nonideal conditions S15 is critical for assembly. The viability of this strain indicates that in vivo functional populations of $70 \mathrm{~S}$ ribosomes must form in the absence of S15 and that 30S subunit assembly has a plasicity that has not previously been revealed or characterized.
\end{abstract}

Keywords: ribosomal proteins; 30S subunit assembly; S15

\section{INTRODUCTION}

Ribosomes are essential, highly abundant components of all cells. In Escherichia coli, ribosomes can account for as much as $45 \%$ of the total mass of these cells, and ribosome biogenesis can consume up to $40 \%$ of the total energy production of E. coli. Also, the rate of ribosome biosynthesis is directly correlated to the rate of bacterial cell proliferation. These observations suggest that a detailed understanding of the interrelated processes of synthesis and subsequent assembly of ribosomal components is critical to our understanding of cell physiology and viability.

\footnotetext{
${ }^{5}$ Present address: Department of Biochemistry and Biophysics, University of Rochester Medical Center, Rochester, NY 14642, USA.

Reprint requests to: Gloria M. Culver, 4216 Molecular Biology Building, Department of Biochemistry, Biophysics and Molecular Biology, Iowa State University, Ames, IA 50011, USA; e-mail: gculver@iastate.edu; fax: (515) 294-0453.

Article published online ahead of print. Article and publication date are at http://www.rnajournal.org/cgi/doi/10.1261/rna.2262106.
}

The 30S, small subunit of the E. coli ribosome is comprised of one large ribosomal RNA (rRNA), 16S rRNA, and 21 unique ribosomal proteins (r-proteins: S1-S21). In spite of this high level of complexity, it has been demonstrated that functional versions of these ribosomal subunits can be reconstituted in vitro (Traub et al. 1967). These in vitro experiments have been used to demonstrate that $30 \mathrm{~S}$ particles assemble in a concerted and hierarchical manner (Fig. 1; Traub et al. 1967; Mizushima and Nomura 1970; Held et al. 1973, 1974). This in vitro assembly system has also allowed the r-proteins to be characterized into different assembly classes depending on their ability to associate directly with naked 16S rRNA (primary binding proteins) or with a $16 \mathrm{~S}$ rRNA-containing ribonucleoprotein particle (RNP: secondary and tertiary binding proteins; Fig. 1A). Thus, the primary binding proteins are thought to be especially critical for orchestrating events during assembly of functional $30 \mathrm{~S}$ subunits.

Assembly results in the organization of the $30 \mathrm{~S}$ ribosomal components into three distinct structural domains 
A

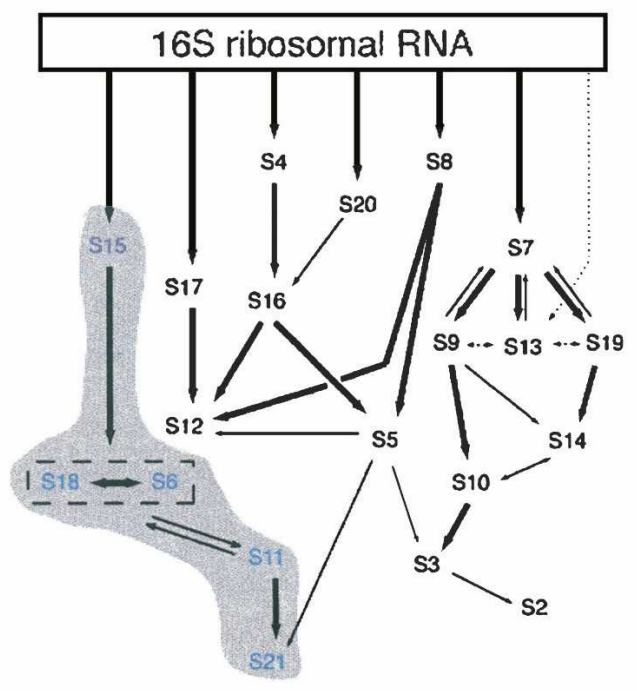

B

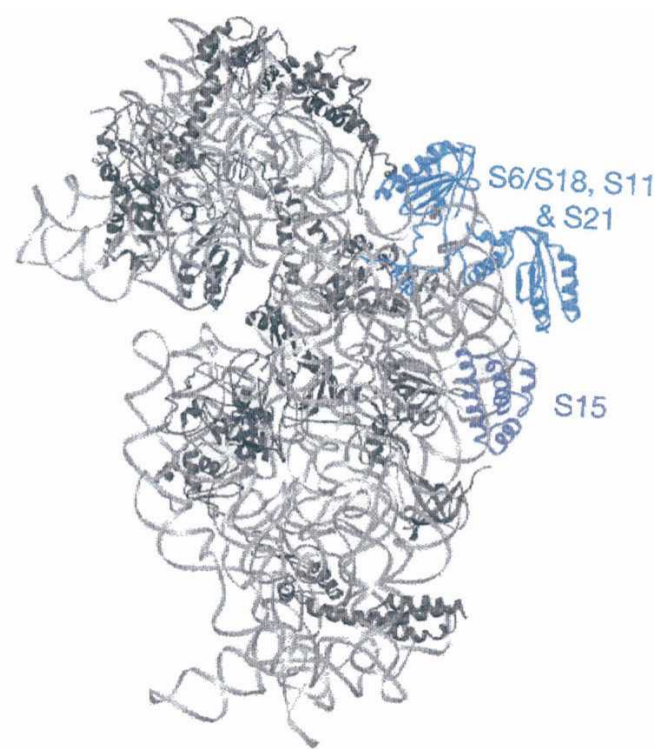

FIGURE 1. The S15 assembly branch in 30 S subunits. (A) In vitro 30 S subunit assembly map (Mizushima and Nomura 1970; Held et al. 1974; Grondek and Culver 2004). 16S rRNA is represented as a rectangle. Arrows indicate interactions between components. S15 is bright blue, S6, S11, S18, and S21 are cyan. S6 and S18 are shown in a dashed line box to indicate that they bind as a heterodimer. The r-proteins in the S15 assembly branch are indicated in gray underlay. All other r-proteins are shown in gray. (B) Position of S15 and related r-proteins in the $30 \mathrm{~S}$ subunit of E. coli. The three-dimensional structure of the $30 \mathrm{~S}$ subunit from E. coli $70 \mathrm{~S}$ ribosomes is shown (Schuwirth et al. 2005). $16 \mathrm{~S}$ rRNA is shown in gray. R-proteins are colored as in A. Ribbons (Carson 1997) was used to prepare this panel and for Figure 7B.

(the head, body, and platform) within the mature 30S subunit (Wimberly et al. 2000). Each structural domain is composed of a portion of $16 \mathrm{~S}$ rRNA, corresponding to a secondary structural element $\left(5^{\prime}\right.$, central, or $3^{\prime}$ major domain), and a subset of the r-proteins. For example, the platform of the $30 \mathrm{~S}$ subunit forms upon association of the r-proteins S15, S6, S18, S11, and S21 with the central domain of the $16 \mathrm{~S}$ rRNA (Fig. 1B). The assembly pathways for each of the domains have been dissected in vitro, and association dependencies between r-proteins is illustrated in an in vitro assembly map for the 30 S subunits (Fig. 1; Mizushima and Nomura 1970; Held et al. 1974; Grondek and Culver 2004).

The r-protein S15 is the sole primary binding protein located in the platform of the $30 \mathrm{~S}$ subunit. S15 binds to the central domain of the 16S rRNA and serves to organize this region of the structure, allowing further assembly to ensue. In vitro reconstitution experiments have shown that the prior association of S15 with $16 \mathrm{~S}$ rRNA is required for the secondary and tertiary r-proteins, S6, S18, S11, and S21, to bind to the emerging complex (Mizushima and Nomura 1970; Held et al. 1974; see Fig. 1). Results from in vitro reconstitutions where single r-proteins were omitted suggest that each of the r-proteins in the S15 assembly branch influences the functional capacity of $30 \mathrm{~S}$ subunits (Nomura et al. 1969). Additionally, isothermal titration calorimetry studies indicated that the S6/S18 heterodimer does not bind to 16S rRNA in the absence of S15 (Recht and Williamson 2001). Thus, the assembly of S6, S18, S11, and S21 appears to be directly dependent on formation of an S15-16S rRNA complex in vitro. R-protein S15 has also been identified as a component of an interface bridge that forms between the $30 \mathrm{~S}$ and $50 \mathrm{~S}$ subunits in the functional 70 S ribosome (Culver et al. 1999; Yusupov et al. 2001). This observation suggests that S15 is involved in subunit association as well as performing a significant role in $30 \mathrm{~S}$ subunit assembly.

While 30 S subunit assembly has been studied extensively in vitro, much less is known regarding this intricate process in vivo. To gain a better understanding of ribosome biogenesis in vivo and to further dissect the role of S15 in this process, we examined the importance of the gene encoding $\mathrm{S} 15, r p s \mathrm{O}$, on cell viability and ribosome biosynthesis. Remarkably, an in-frame chromosomal deletion of $r p s O$ (designated $\Delta r p s O$ ) yields a viable E. coli strain, demonstrating that functional ribosomes lacking S15 are able to assemble in vivo, contrary to expectations based on much in vitro data. The $\Delta r p s O$ strain is slow growing even at the permissive temperature $\left(37^{\circ} \mathrm{C}\right)$; further it displays a coldsensitive phenotype, which is typical of bacterial strains with ribosomal assembly defects (for examples, see Guthrie et al. 1969; Dammel and Noller 1993). We have analyzed the formation of ribosomes under permissive and nonpermissive growth conditions in the $\Delta r p s O$ strain using sucrose gradient sedimentation, two-dimensional gel electrophoresis, chemical probing, and primer extension analysis to understand the nature of ribosomes and ribosome biogenesis in E. coli lacking r-protein S15. Our findings 
suggest that the lack of S15 is detrimental to 70S ribosome formation and $30 \mathrm{~S}$ subunit biogenesis. However, our results also suggest that neither assembly of the platform of the $30 \mathrm{~S}$ subunit nor formation of functional $70 \mathrm{~S}$ ribosomes is absolutely dependent on S15 in vivo. These data reveal a remarkable level of plasticity and perhaps redundancy in ribosome assembly and function in vivo that has not been observed in vitro.

\section{RESULTS}

\section{Construction of the $r p s O$ deletion strain}

The $\Delta r p s O$ E. coli cells were constructed so as to precisely remove the entire rpsO orf from the chromosome without affecting the expression of neighboring genes. Unlike many other operons that encode r-proteins, the operon in which rpsO resides is small and contains no other r-protein genes (Zengel and Lindahl 1994). The in vivo genetic technique of precise manipulation of chromosomal genes, called recombineering (Court et al. 2002), was used for this purpose. It is based on recombinogenic functions of the phage $\lambda$ red genes, which, upon induction in a host from a $\lambda$ prophage or a plasmid, promote efficient recombination in enteric bacteria using short 40-50 nt flanking homologies (Court et al. 2002; Thomason et al. 2005a,b). This technique has turned out to be exceptionally useful for construction of $E$. coli chromosomal gene knockouts. In this case, a chromosomal gene orf can be precisely replaced with an orf of a drug cassette, thus allowing positive selection for the gene knockout. Such a replacement should not have nonspecific polar effects on the expression of genes flanking the replaced gene; thus changes in cell function can be directly attributed to the absence of this gene (Yu et al. 2000; M. Bubunenko and D.L. Court, in prep. data not shown).

Using recombineering, we created a S15 knockout by precisely replacing the $r p s O$ orf with the kan gene orf. This recombination occurred at the same high frequency $\left(\sim 10^{-4}\right)$ as for recombination with any nonessential gene on the chromosome even in the absence of a complementing rpsO-containing plasmid, despite expectations of an essential role of S15 in the ribosome assembly (Mizushima and Nomura 1970; Held et al. 1974). The kanamycinresistant $\left(\mathrm{Km}^{\mathrm{R}}\right)$ recombinants appeared to be viable, albeit slow growing. The S15 knockout was then transferred to a W3110 wild-type background by P1 transduction to study its effect on cell growth and formation of ribosomes in vivo.

\section{Growth phenotypes associated with the $\Delta r p s O$ strain}

It was immediately evident that deletion of the gene encoding r-protein $\mathrm{S} 15(\Delta r p s O)$ resulted in a viable strain, yet one with altered growth properties (Fig. 2). The $\Delta r p s O$ strain grows more slowly than its parental strain even in

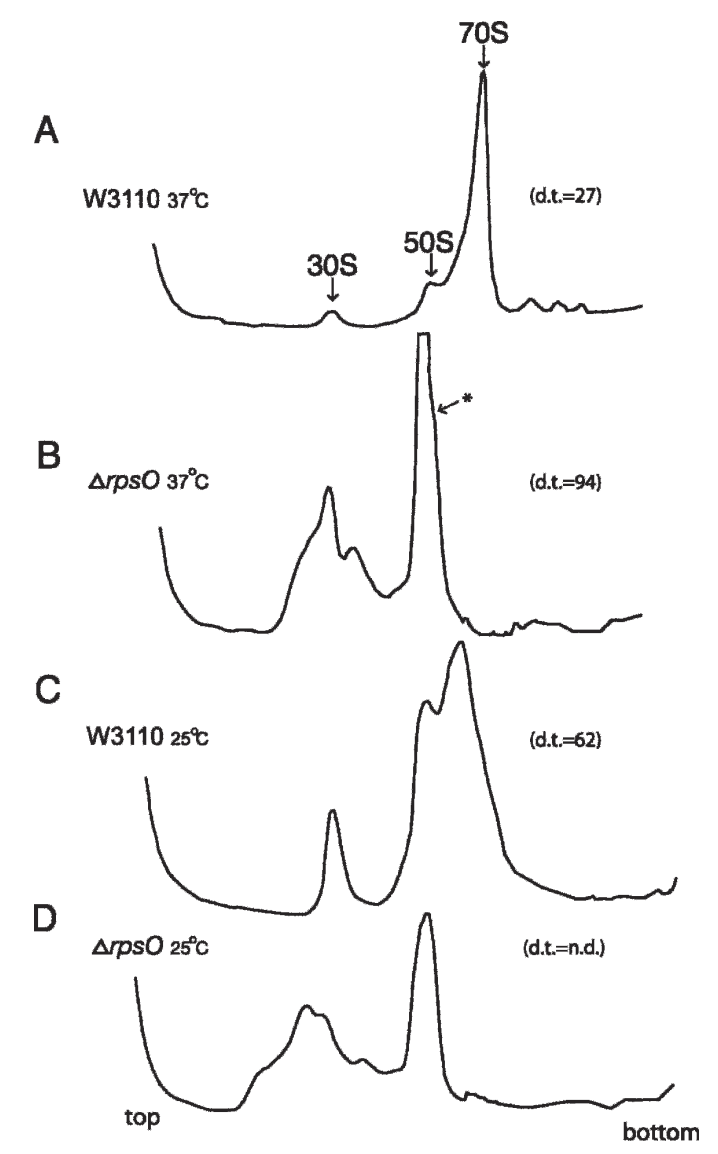

FIGURE 2. Sucrose gradient sedimentation analysis of polysomes profiles. Sucrose gradient sedimentation analysis of polysomes isolated from $\Delta r p s O$ mutant grown under various conditions. Top and bottom of gradients are indicated and absorbance was monitored at $254 \mathrm{~nm}$. Positions of $30 \mathrm{~S}$ and $50 \mathrm{~S}$ subunits and $70 \mathrm{~S}$ ribosomes are indicated. (A) $\mathrm{W} 3110,37^{\circ} \mathrm{C}$; parental (wild-type) strain grown at $37^{\circ} \mathrm{C} /$ permissive temperature. (B) $\Delta r p s O, 37^{\circ} \mathrm{C} ; \Delta r p s O$ strain grown at $37^{\circ} \mathrm{C} /$ permissive temperature. $(C) \mathrm{W} 3110,25^{\circ} \mathrm{C}$; parental (wild-type) strain grown at $25^{\circ} \mathrm{C} /$ nonpermissive temperature. (D) $\Delta r p s O, 25^{\circ} \mathrm{C}$; $\Delta r p s O$ strain grown at $25^{\circ} \mathrm{C} /$ nonpermissive temperature.

rich media under normal growth conditions $\left(37^{\circ} \mathrm{C}\right)$; the doubling time for $\Delta r p s O$ is $\sim 90 \mathrm{~min}$, while it is $30 \mathrm{~min}$ for the parental strain under the same conditions (Fig. 2A,B). Deletion of the $\mathrm{rps} O$ orf leads to a cold-sensitive phenotype (estimated doubling time of $>660 \mathrm{~min}$ at $25^{\circ} \mathrm{C}$; Fig. 2C,D). Cold sensitivity is a standard hallmark of many strains that have defects in ribosome biogenesis (see, for example, Dammel and Noller 1993, 1995) and is thus consistent with the deletion of an r-protein with links to ribosome biogenesis. These results suggest that $E$. coli can survive in theabsence of S15 but that the resulting strain is somewhat compromised.

\section{Ribosome formation in the $\Delta r p s O$ strain}

Ribosome profiles from the mutant and parental strains were examined under permissive and nonpermissive conditions to determine if deletion of rpsO led to defects in 
ribosome biosynthesis. Under permissive conditions, there are aberrations apparent in the ribosomes isolated from the $\Delta r p s O$ strain (Fig. 2, cf. A and B). Strikingly, very few $70 \mathrm{~S}$ ribosomes or polysomes are present in the mutant strain (Fig. 2B) compared to the parental strain (Fig. 2A). A small shoulder on the 50S subunit (asterisk in Fig. 2B) could represent a small population of $70 \mathrm{~S}$ ribosomes. It is obvious that functional $70 \mathrm{~S}$ ribosomes formation is a prerequisite given the viability of this strain; however under standard conditions we are generally unable to detect a substantial population of $70 S$ ribosomes. Our data could be explained by an alteration, such as decreased stability, of the interaction between the $30 \mathrm{~S}$ and $50 \mathrm{~S}$ subunits in the strain lacking S15. Since S15 is involved in forming a bridge between the subunits, this seems like the simplest and most plausible explanation. While $30 \mathrm{~S}$ and $50 \mathrm{~S}$ subunit peaks are present in the deletion strain, there are additional species in the profiles. These additional peaks are reminiscent of those observed in strains with ribosome biogenesis defects (Guthrie et al. 1969). These data suggest that even at the permissive temperature, ribosome biogenesis is affected by the deletion of $\mathrm{S} 15$, as is $70 \mathrm{~S}$ ribosome formation. The exaggerated doubling time of the deletion strain at $37^{\circ} \mathrm{C}$ may reflect the production of fewer subunits and functional ribosomes in the absence of S15.

To examine changes related to the cold-sensitive phenotype, ribosome profiles from both the parental and S15 deletion strains grown at the nonpermissive temperature were analyzed. The profiles are slightly altered when the parental strain (W3110) is shifted to $25^{\circ} \mathrm{C}$ compared with continued growth at $37^{\circ} \mathrm{C}$ (Fig. 2, cf. A and C). More free subunits are observed in the parental strain grown at low temperature; this observation would be consistent with the increased doubling time of $\mathrm{W} 3110$ at $25^{\circ} \mathrm{C}$. More significantly, when the $\Delta r p s O$ strain is shifted from the permissive temperature to the nonpermissive (low) temperature, there is a further alteration in the already abnormal profiles (Fig. 2, cf. B and D). Under these conditions, a peak corresponding to $50 \mathrm{~S}$ subunits is apparent, although a $30 \mathrm{~S}$ subunit peak is not readily discernible and a series of novel peaks appears in the profiles (Fig. 2D). These results are consistent with defects in ribosome subunit biogenesis and perhaps in the stability of 30 S subunits formed in the absence of S15.

To determine if the emerging peaks, which are observed at low temperature in the deletion strain, correspond to precursors in the $30 \mathrm{~S}$ subunit assembly pathway, these additional species were analyzed for mature and precursor $16 \mathrm{~S}$ rRNA as compared to particles formed in the parental strain under similar growth conditions (Fig. 3). Primer extension analysis reveals that $16 \mathrm{~S}$ rRNA is a component of these particles, and in the mutant background the majority of the rRNA is not fully processed at the $5^{\prime}$ end (Fig. 3 , cf. $\Delta r p s O$ and W3110 lanes). These results suggest that the novel peaks are pre-30S particles that form in the absence of S15 in vivo. These results are consistent with a link
A

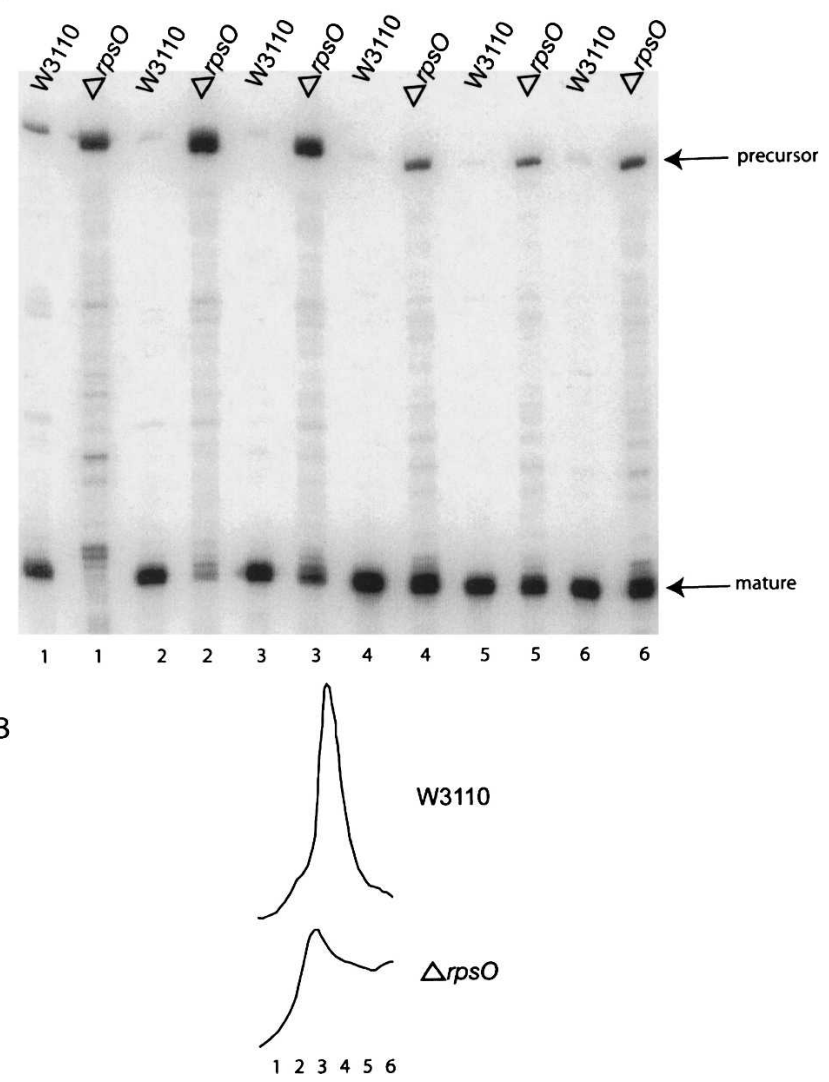

FIGURE 3. Primer extension analysis of $16 \mathrm{~S}$ rRNA isolated from ribosome profiles. (A) Autoradiogram of a primer extension with RNA isolated from fractions from either the wild-type/parental strain $\mathrm{W} 3110$ or $\Delta r p s O$ both grown at $25^{\circ} \mathrm{C}$. Primer $161-16 \mathrm{~S}$ rRNA is shown and the mature $5^{\prime}$ and the predominant precursor $(-123)$ ends of the RNA are indicated. $(B)$ Portions of the profiles from which RNA was isolated (fractions 1-6) are shown. The numbers at the bottom of the gel lanes correspond to the regions of the gradients as indicated.

between deletion of S15, cold sensitivity, 16S rRNA processing, and ribosome biogenesis.

Since r-protein S15 is known to participate in one of the bridges between $30 \mathrm{~S}$ and 50 S subunits (Culver et al. 1999), it is possible that $70 \mathrm{~S}$ ribosomes formed in the absence of S15 have altered stability and dissociate during the course of isolation and sucrose gradient sedimentation. This would be consistent with the observed deficit of $70 \mathrm{~S}$ ribosomes in the polysome profiles (Fig. 2B). To further explore this possibility, $30 \mathrm{~S}$ subunits formed in vivo in the absence of S15 (but at the permissive temperature) were assayed to determine if their ability to participate in subunit association was altered. $30 \mathrm{~S}$ subunits isolated from $\Delta r p s O$ (Fig. 4D) are unable to associate with natural 50S subunits isolated from either the mutant (Fig. 4F) or parental (Fig. 4G) strain. These results indicate that under standard conditions, which support association of wildtype subunits (Fig. 4C), 30S subunits lacking S15 are 

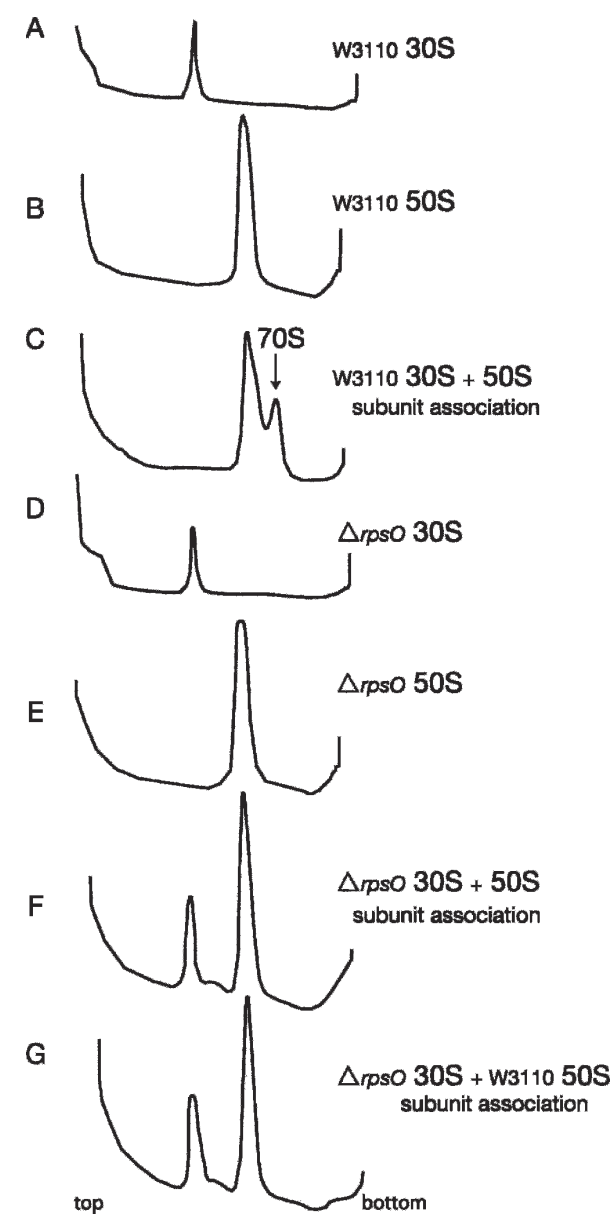

FIGURE 4. Sedimentation analysis of ribosomal subunit association using subunits isolated from $\Delta r p s O$ and parental strains under associating conditions. Sedimentation is from left to right, and the top and bottom of the gradients are indicated. Absorbance was monitored at $254 \mathrm{~nm}$. The position of $70 \mathrm{~S}$ ribosomes is marked by an arrow. (A) W3110 30S; Natural $30 \mathrm{~S}$ subunits (30 pmol) isolated from W3110 grown at $37^{\circ} \mathrm{C}$ (permissive conditions). (B) W3110 50S; $50 \mathrm{~S}$ subunits $(50 \mathrm{pmol})$ isolated from $\mathrm{W} 3110$ grown at $37^{\circ} \mathrm{C}$ (permissive conditions). (C) W3110 30S2 + 250S subunit association; W3110 $30 \mathrm{~S}$ (as in $A$ ) and $50 \mathrm{~S}$ (as in $B$ ) subunits incubated under conditions to yield $70 \mathrm{~S}$ ribosomes. (D) $\Delta r p s O 30 \mathrm{~S}$; Natural $30 \mathrm{~S}$ subunits (30 pmol) isolated from $\Delta r p s O$ grown at $37^{\circ} \mathrm{C}$ (permissive conditions). (E) $\Delta r p s O$ 50S; $50 \mathrm{~S}$ subunits $(50 \mathrm{pmol})$ isolated from $\Delta r p s O$ grown at $37^{\circ} \mathrm{C}$ (permissive conditions). (F) $\Delta r p s O 30 \mathrm{~S} 2+250 \mathrm{~S}$ subunit association; $\Delta r p s O 30 \mathrm{~S}$ (as in $D$ ) and $50 \mathrm{~S}$ (as in $E$ ) subunits incubated under conditions to yield $70 \mathrm{~S}$ ribosomes. $(G) \Delta r p s O 30 \mathrm{~S} 2+2 \mathrm{~W} 311050 \mathrm{~S}$ subunit association; $\Delta r p s O 30 \mathrm{~S}$ subunits (as in $D$ ) and W3110 $50 \mathrm{~S}$ subunits (as in $B$ ) incubated under conditions to yield 70 S ribosomes.

defective in subunit association. Also, varying the $\mathrm{MgCl}_{2}$ concentration from 5 to $25 \mathrm{mM}$ did not alter the results (data not shown). In contrast, $50 \mathrm{~S}$ subunit isolated from the deletion strain can associate with wild-type $30 \mathrm{~S}$ subunits (data not shown). These data suggest that $30 \mathrm{~S}$ subunits formed in the absence of S15 are compromised for function, while the 50S subunits are not. Nevertheless, a population of functional 70S ribosomes must be formed in vivo in $\Delta r p s O$, given the viability of this strain. The slight shoulder on the 50 S subunit observed in ribosome profiles from this strain (see Fig. 2B) likely represents a small population of $70 \mathrm{~S}$ ribosomes, which is adequate for viability. Thus the absence of S15 may impact the stability of 70 S ribosomes, which could, at least partially, account for the extended doubling time of the $\Delta r p s O$ strain even at permissive conditions (see Fig. 2).

\section{Structure of ribosomes formed in the absence of S15}

Results from in vitro experiments indicate that in the absence of S15, there should be little to no assembly of S6, S18, S11, or S21 onto the 30 S subunit and that the resulting RNPs should be significantly compromised for function (Nomura et al. 1969; Mizushima and Nomura 1970; Held et al. 1974; Recht and Williamson 2001). Given the somewhat contradictory nature of these in vitro results and the viability of the $\Delta r p s O$ strain, the protein composition and folding of $16 \mathrm{~S}$ rRNA in mutant subunits was examined.

Two-dimensional gel electrophoretic analysis was undertaken to compare the r-protein components of ribosomes isolated from the parental and $\Delta r p s O$ strain (Fig. 5). These data reveal that ribosomes isolated from the $\Delta r p s O$ strain contain r-proteins S6, S18, S11, and S21 as constituents of the RNP (Fig. 5B). As expected, r-protein S15 is lacking from the subunits isolated from $\Delta r p s O$ but is present in the two-dimensional profiles of ribosomes isolated from the parental strain (Fig. 5 cf. B with A). Thus, in vivo $\mathrm{S} 15$ is dispensable for the association of the platform proteins, S6, S11, S18, and S21. These results are somewhat at odds with in vitro data that indicates a direct role for S15 in the assembly of these proteins (Nomura et al. 1969; Mizushima and Nomura 1970; Held et al. 1974; Recht and Williamson 2001). These data suggest that alternative assembly pathways exist in vivo that have not been revealed by in vitro experimentation.

Given that S6, S11, S18, and S21 are present in these 30S particles and that they likely assembled via an unexplored pathway, the structure of the 30 S subunit in the vicinity of these proteins was of great interest. The folding of $16 \mathrm{~S}$ rRNA and footprints attributable to the platform r-proteins were examined in the parental strain, W3110, the deletion strain, $\Delta r p s O$, and a standard strain for ribosome analysis, MRE600, using chemical probing and primer extension analysis (Moazed et al. 1986). The accessibility of nucleotides in $16 \mathrm{~S}$ rRNA in subunits isolated from the deletion strain does not appear to be globally different from the reactivity of nucleotides in either of the wild-type subunits (Fig. 6; data not shown). However, the protections that are generally attributed to S15 (Svensson et al. 1988; Powers and Noller 1995) are missing in the mutant ribosomes (Fig. 6A for hydroxyl radicals, Fig. 6B,C for DMS, and Fig. 6D for kethoxal). Distinct changes in the reactivity of $16 \mathrm{~S}$ rRNA in subunits isolated from the $\Delta r p s O$ strain are seen in the region from 720 to 750 (Figs. 6A,C,D, 7). While the majority of sites with 

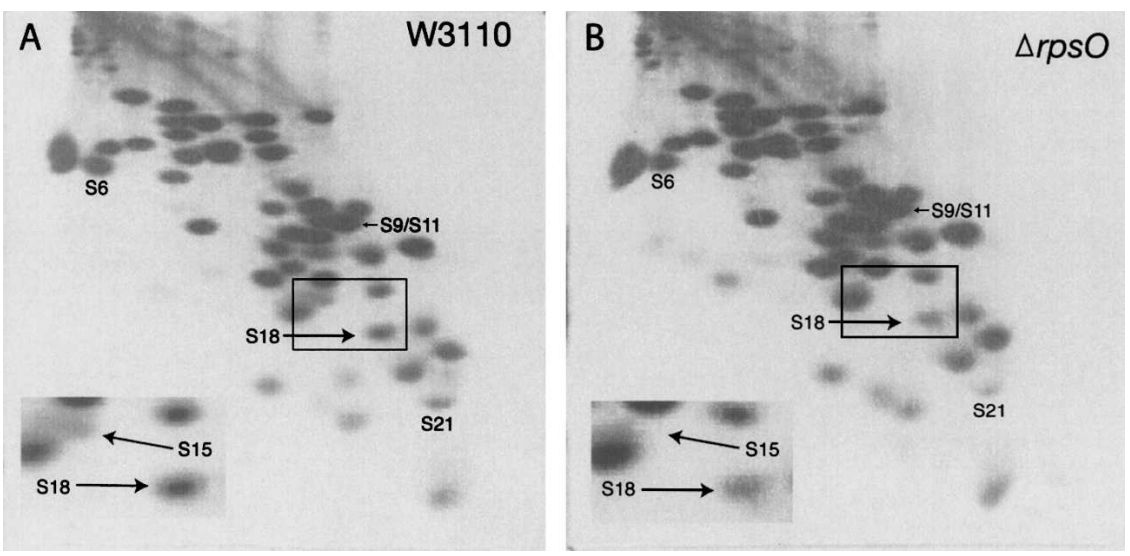

FIGURE 5. Analysis of protein composition of ribosomal subunits by two-dimensional gel electrophoresis. The positions of r-proteins found in the S15 assembly branch are indicated. The region of the gels where r-proteins $\mathrm{S} 15$ and S18 migrate is enlarged in the insert. $(A)$ W3110, parental; ribosomal proteins isolated from W3110. (B) $\Delta r p s O$, ribosomal proteins isolated from $\Delta r p s O$.

increased reactivity in the subunits lacking S15 correspond directly with sites footprinted by S15 (Svensson et al. 1988; Powers and Noller 1995), three additional changes are also observed. Nucleotides 655, 722, and 733 all display increased reactivity (Figs. 6, 7), which cannot be explained simply by the absence of S15 or misbinding of the S15-dependent r-proteins. These positions are adjacent to S15 footprint and contact sites (Fig. 7), suggesting that the absence of $S 15$ causes minor "local" changes in the conformation of 16S rRNA. In contrast, the modification patterns of the central domain of $16 \mathrm{~S}$ rRNA in regions where S6, S18, and S11 footprint the RNA are virtually indistinguishable between the wild-type and $\Delta r p s O$ strains (Fig. 6; Svensson et al. 1988). Due to the minimal amount of footprinting data for S21 (1 nt) (Stern et al. 1988), it is difficult to definitely speak to nature of its interaction with $16 \mathrm{~S} \mathrm{rRNA}$, although the data are consistent with uncompromised association of this protein as well (Fig. 5B). Taken together, analysis of r-protein composition and $16 \mathrm{~S}$ rRNA modification patterns reveal that in the absence of S15 in vivo neither the binding of the platform proteins nor the overall conformation of $16 \mathrm{~S}$ rRNA greatly altered, although slight differences in rRNA residues immediately adjacent to the S15 binding site are observed. These results suggest that the four platform r-proteins, S6, S11, S18, and S21, can associate with 30 S subunits in an S15-indendent manner in vivo and thus reveals that alternative 30 S subunit assembly pathways must exist in vivo that were not observed by in vitro experimentation.

\section{DISCUSSION}

An E. coli strain with an in-frame deletion of $r p s O$, the gene encoding r-protein $\mathrm{S} 15$, has been isolated and characterized. While viable, this strain is compromised for growth and is cold sensitive. Under standard growth conditions only r-protein S15 appears to be absent from the ribosomal particles and the overall conformation of $16 \mathrm{~S}$ rRNA in these ribosomes appears to be similar to wild-type ribosomes. Nevertheless, the relative amount of 70S ribosomes observed in this strain is diminished relative to the parental strain, and 30 S subunits lacking S15 appear to be impaired for subunit association as monitored in vitro. These results suggest that under optimal growth conditions, S15 is not essential for ribosome formation and cell growth. However, at low temperature, S15 appears to be essential for viability, and a ribosome biogenesis defect is apparent under these conditions. Thus although alternative pathways for assembly of the platform of the $30 \mathrm{~S}$ subunit appear to exist in vivo, these pathways do not appear to be sufficiently robust to support growth under nonoptimal conditions.

Many in vitro experiments have reported the requirement of prior association of S15 with 16S rRNA before binding of four additional r-proteins, S6, S18, S11, and S21. These in vitro results are quite compelling, and the S15-dependencies have been observed by a variety of techniques. Nonetheless, in vivo these four r-proteins can assemble onto ribosomal particles in the absence of S15 (see Fig. 5). While these five r-proteins are all located in the platform of the 30 S subunit (Svensson et al. 1988; Agalarov et al. 1999; Wimberly et al. 2000; Schuwirth et al. 2005), there are no direct protein-protein contacts between S15 and any of the platform proteins (S21 is absent from the Thermus thermophilus $30 \mathrm{~S}$ subunit and therefore from the high-resolution structure of $30 \mathrm{~S}$ subunits [Agalarov et al. 2000; Wimberly et al. 2000; Brodersen et al. 2002] but is present in the recent E. coli $70 \mathrm{~S}$ ribosome structure [Schuwirth et al. 2005]). The lack of direct contact between S15 and the other r-proteins in its assembly branch has led to the speculation that S15 binding to $16 \mathrm{~S}$ rRNA causes a conformational rearrangement that results in the formation of the binding sites for the other platform proteins. An S15-induced conformational shift in 16S rRNA has been observed in a minimal system (Orr et al. 1998). Also, using this minimal system it has been observed that $\mathrm{Mg}^{2+}$ can cause a similar change in $16 \mathrm{~S}$ rRNA conformation. Since the absence of S15 from the 16S RNP would not directly remove contact surface for these later assembling $\mathrm{r}$ proteins, it is possible that in vivo the conformation of $16 \mathrm{~S}$ rRNA required for binding of S6, S18, S11, and S21 can arise in the absence of S15 and thus assembly of the platform can proceed. 

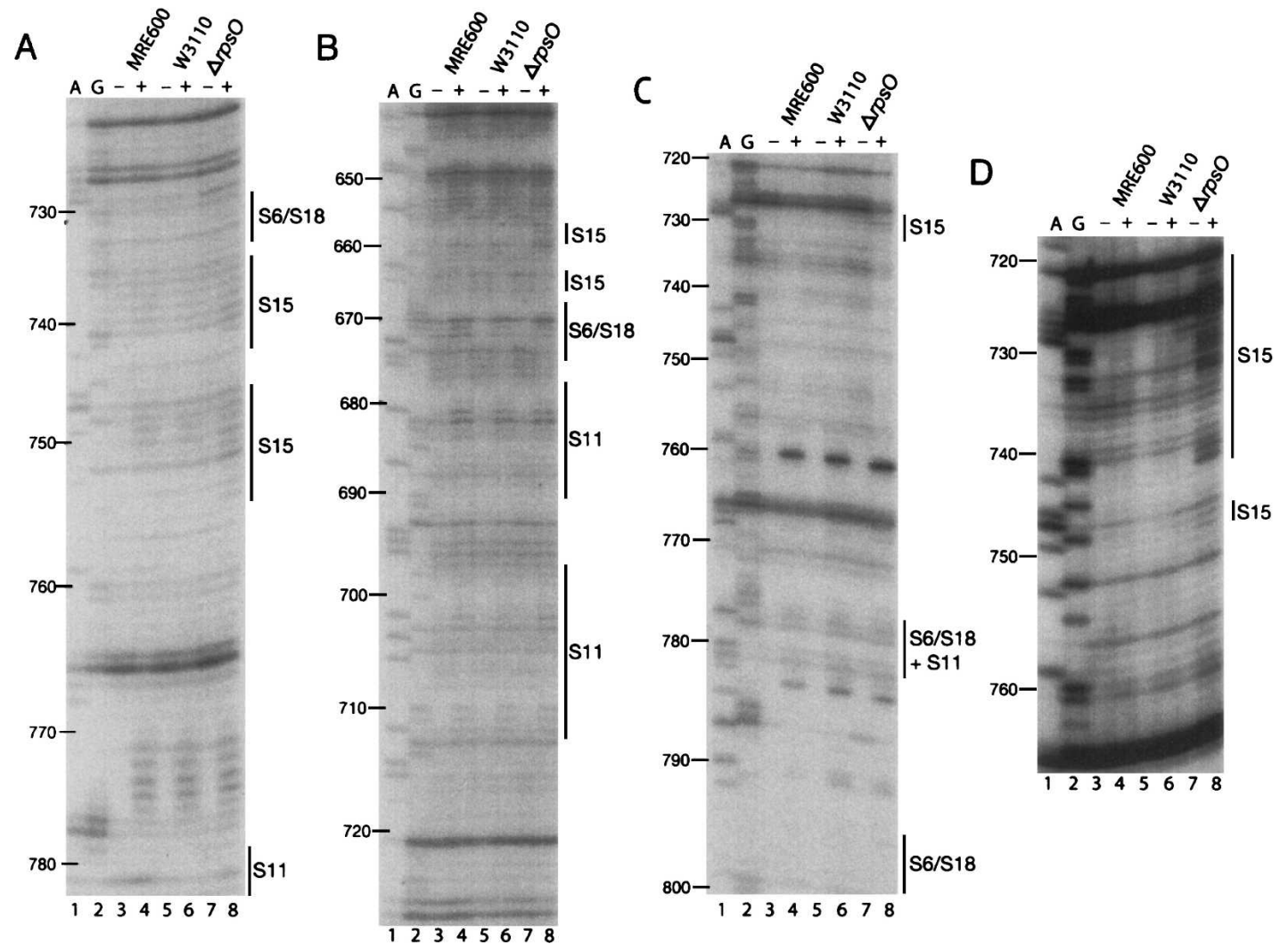

FIGURE 6. Chemical modification of $16 \mathrm{~S}$ rRNA nucleotides in $30 \mathrm{~S}$ subunits detected by primer extension. Samples are either modified $(+)$ or not (-) with $(A)$ hydroxyl radical, $(B)$ and $(C)$ DMS, or $(D)$ kethoxal; Lanes 1 and 2 are A and G sequencing lanes, respectively; lanes 3 and 4 are $30 \mathrm{~S}$ subunits isolated from MRE600; lanes 5 and 6 are $30 \mathrm{~S}$ subunits isolated from W3110, and lanes 7 and 8 are $30 \mathrm{~S}$ subunits isolated from $\Delta r p s O$. Regions footprinted by r-proteins from the S15 assembly branch are shown and specific regions are indicated by bars and the r-protein that has been assigned as the effector in that region (see Svensson et al. 1988; Powers \& Noller 1995). Primer 795 was used for panels $A, B$, and $D$ and primer 836 was used for panel $C$.

Chemical probing and primer extension analysis of ribosomes lacking S15 (see Figs. 6, 7) reveals that the folding of $16 \mathrm{~S}$ rRNA is not greatly altered relative to wildtype ribosomes. As expected, the nucleotides that have been identified as being footprinted by S15 (Svensson et al. 1988 Powers and Noller 1995) are generally more reactive in the $\Delta r p s O 30 \mathrm{~S}$ subunits than in the parental subunits. In addition to the $S 15$ footprinting sites, there are three additional nucleotides, which are all immediately adjacent to sites footprinted by S15 that also show increased reactivity. These sites are not known to be footprinted by any of the other platform proteins (Svensson et al. 1988; Powers and Noller 1995) and two of the three, A655 and G733, do not appear to be directly contacted by any of the r-proteins (Wimberly et al. 2000; Schuwirth et al. 2005). However, one of the sites, G722, is in contact with S18 in the structure of the E. coli 30 S subunit from the 70 S ribosome (Schuwirth et al. 2005). Thus, it is possible that the association of S18 is slightly altered in the absence of S15. Alternatively, it is possible that this is a region with conformational flexibility. This later possibility is consistent with the lack of interaction between G722 and S18 in the structure of the T. thermophilus $30 \mathrm{~S}$ subunits (Wimberly et al. 2000). These observations suggest that in the absence of S15, the overall conformation of the subunits is not greatly altered, but that subtle changes are observed. The viability of this strain suggests that these alterations to not have a gross impact on ribosome function.

It is possible that assembly in the absence of S15 is less effective/efficient than when it is present, which could account for the increase in doubling time for the $\Delta r p s O$ strain compared to the parental strain at the permissive temperature (see Fig. 2). Alternatively the increased doubling time could be due to a defect in subunit association (see Figs. 2, 3). While a functional population of $70 \mathrm{~S}$ ribosomes must be formed in vivo in the $\Delta r p s O$ strain, we were unable to detect a significant population of such ribosomes. Ribosomes isolated and analyzed directly from the deletion strain reveal a marked lack of $70 S$ ribosomes (Fig. 2B) and attempts to associate the $30 \mathrm{~S}$ subunits lacking S15 in vitro with natural 50S subunits (Fig. 4F,G) also fail to demonstrate formation of $70 \mathrm{~S}$ ribosomes. Nonetheless, 70 S ribosomes lacking S15 must form in vivo to allow for translation and therefore cell viability. Previous structural 
A

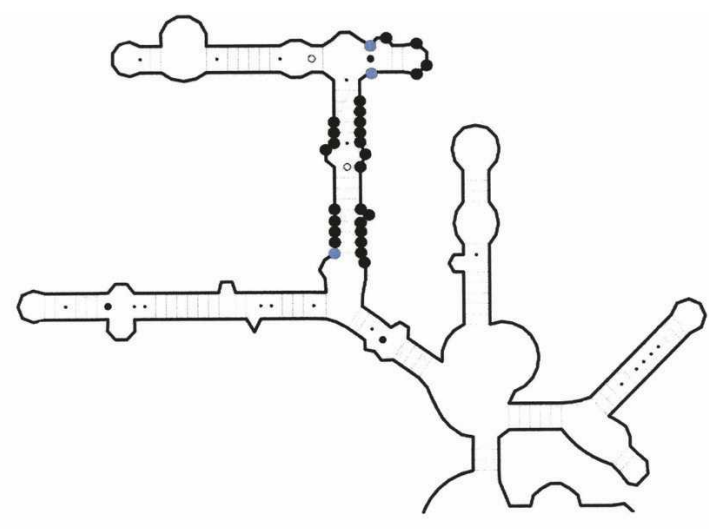

B

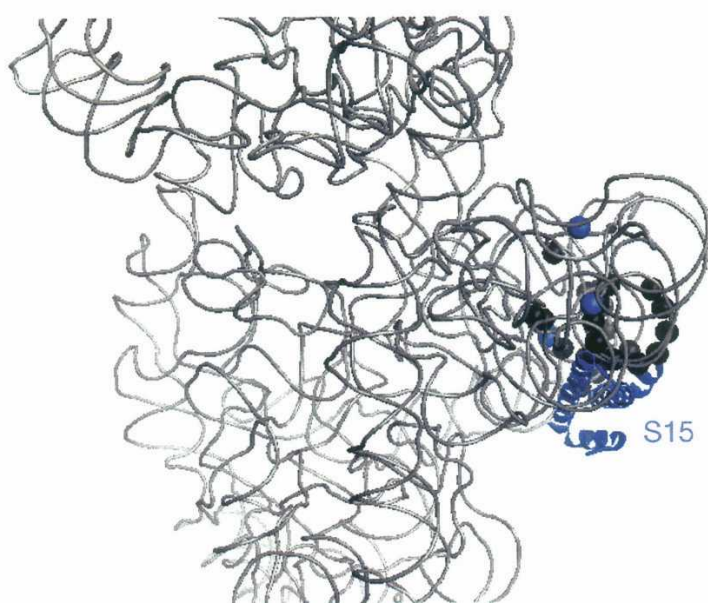

FIGURE 7. Chemical modification differences for the $\Delta r p s O 30 \mathrm{~S}$ subunits mapped on $16 \mathrm{~S}$ rRNA. (A) Changes in reactivity observed in the $\Delta r p s O 30$ s subunits that are consistent with previous work are shown as black circles on the secondary structure of the central domain of $16 \mathrm{~S}$ rRNA (Cannone et al. 2002). Changes in reactivity that are not explained by earlier footprinting studies are shown as blue circles. (B) Changes in reactivity observed in the $\Delta r p s O 30 \mathrm{~S}$ subunits are shown on a portion of the tertiary structure of $16 \mathrm{~S}$ rRNA from E. coli 70 S ribosomes (Schuwirth et al. 2005). 16S rRNA is shown in gray and nucleotides with altered reactivities are colored as indicated in panel A. S15 is shown in blue and all other r-proteins are omitted for clarity.

and biochemical work (Culver et al. 1999; Yusupov et al. 2001) has indicated that $S 15$ is involved in forming the B4 bridge between the $30 \mathrm{~S}$ and $50 \mathrm{~S}$ subunits. However, this is only one of 12 bridge elements and one of the two where the element contributed by the $30 \mathrm{~S}$ subunit is an r-protein; the second is the B1 bridge in which $\mathrm{S} 13$ is involved (Yusupov et al. 2001). Interestingly, it was recently demonstrated that the gene encoding r-protein S13, rpsM, could, under specific conditions, also be deleted from E. coli (Cukras and Green 2005). Similar to the results presented here, the $\Delta r p s M$ strain has a slow growth phenotype and a marked defect in subunit association in vitro and in vivo. Thus, it is likely that the absence of either small subunit $\mathrm{r}$-protein involved in a bridge with the $50 \mathrm{~S}$ subunit is highly detrimental to the ability of these particles to form stable $70 \mathrm{~S}$ ribosomes. The slow growth phenotypes associated with both deletion strains, under normal growth conditions, suggest that neither strain is as healthy as wild type; however, as both strains are indeed viable, it is likely that other ribosomal or translational components participate in stabilization of functional ribosomes. Thus, it is likely that the slow growth defect of the $\Delta r p s O$ strain that is observed at normal growth conditions is due, at least in part, to the observed defects in subunit association.

Systematic deletion of the genes encoding ribosomal proteins in the budding yeast Saccharomyces cerevisaie has been performed (Ferreira-Cerca et al. 2005). This work revealed that the majority of small subunit r-protein genes are essential for viability in yeast. Of those that were found to be nonessential, reduced levels of rRNA were reported; however, deletion of the genes encoding the nonessential yeast small subunit ribosomal proteins ( $\mathrm{rpS12}$ and $\mathrm{rpS} 25$ ) does not result in altered polysome profiles under standard growth conditions. Thus it would appear that deletion of the nonessential yeast r-protein genes results in effects that are distinct from those presented here for deletion of $r p s O$ in E. coli. It should be noted that the ortholog of E. coli S15 (rpS13) is essential in yeast, and that early events in prerRNA processing are affected by depletion of this protein. Thus, it is possible that these proteins have similar functions in different organisms, but with slightly different phenotypic outcomes. Overall, it is possible that the more complicated processing and transport requirements for rRNA and ribosomes in yeast exact a higher standard, resulting in essential roles for the majority of r-protein genes in yeast.

Defects in ribosome biogenesis are often associated with phenotypic changes in mutant strains, and the most notable is cold sensitivity. The cold-sensitive phenotype associated with deletion of the gene encoding r-protein S15 is highly consistent with a role of S15 in 30S subunit assembly. Defects in $30 \mathrm{~S}$ subunit biogenesis can be observed upon transfer of the strain from permissive to nonpermissive temperature (Figs. 2, 3). Processing of the $5^{\prime}$ end of $16 \mathrm{~S}$ rRNA is clearly altered in the S15 deletion strain and a heterogenous population of precursor particles appears to be formed. It should be noted that deletion of the rps gene encoding S13, does not yield a cold-sensitive phenotype (A.R. Cukras and R. Green, pers. comm.). Thus while there are similarities in terms of subunit association defects and slow growth under normal growth conditions (see above), these findings would suggest that $S 13$ is apparently dispensable for $30 \mathrm{~S}$ subunit assembly. Based on the somewhat isolated position of S13 in the in vitro $30 \mathrm{~S}$ subunit assembly map (see Fig. 1A), the nonessential nature of its gene, vis-àvis $30 \mathrm{~S}$ subunit assembly, does not result in the same quandary as deletion of $r p s O$. Thus it appears that deletion of $r p s O$ has additional changes that cannot be explained as 
simply due to the deletion of an r-protein gene, and the cold-sensitive phenotype is highly consistent with a defect in $30 \mathrm{~S}$ subunit biogenesis that would be expected for deletion of $r p s O$. Dissection of assembly of $30 \mathrm{~S}$ subunits formed in the $\Delta r p s O$ strain and thus further examination of assembly in the absence of S15 may reveal novel pathways for formation of this large macromolecular complex.

\section{MATERIALS AND METHODS}

\section{Media and bacteriological techniques}

Standard bacteriological techniques were used (Miller 1972). Cells were grown in $\mathrm{LB}$ medium containing $25 \mu \mathrm{g} / \mathrm{mL}$ kanamycin $(\mathrm{Km})$, when needed.

\section{Inactivation of $r p s O$ using recombineering}

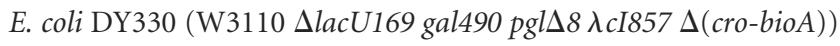
was used for recombineering (Yu et al. 2000). Recombineering was done as detailed (Thomason et al. 2005a) with some modifications. The DY330 cells were grown at $32^{\circ} \mathrm{C}$ to $\mathrm{A}_{600} \cong 0.5$ and the recombinogenic $\lambda$ red functions were induced by shifting the culture to $42^{\circ} \mathrm{C}$ for $15 \mathrm{~min}$. The induced cells were washed with water, transformed with $200 \mathrm{ng}$ of $\mathrm{rpsO}$-inactivating kan cassette by electroporation and let to outgrow at $32^{\circ} \mathrm{C}$ for $2 \mathrm{~h}$. Then they were spread on $\mathrm{LB}-\mathrm{Km}$ plates and incubated at $34^{\circ} \mathrm{C}$ to reveal $\mathrm{Km}$-resistant recombinants; one of these recombinants was charactrerized further and named NB429 (DY330 rpsO<>kan).

The kan cassette for $r p s O$ disruption was made by PCR using the Platinum Taq DNA Polymerase High Fidelity Kit (Invitrogen) according to the manufacturer's protocol. The Tn5 kan gene was amplified with the following pair of primers:

forward primer: ATCGGCGTCCTTTCATTCTATATACTTTGGA GTTTTAAAATGATTGAACAAGATGGATTG, and reverse primer: GGGGCCACTCAGGCCCCCTTTTCTGAAACTC GCAAGAATCAGAAGAACTCGTCAAGAAG.

Both primers contained 39-nt regions (underlined) complementary to $r p s O$ flanking regions so that the kan ORF in the $r p s O$ inactivating cassette precisely replaces the rpsO ORF upon recombineering into the chromosome. $\mathrm{Km}^{\mathrm{R}}$ recombinants were found at a frequency of one in $10^{4}$ of total cells electroporated. Note that inactivation of essential genes by this technique is at least 100 -fold lower than this frequency, whereas inactivation of nonessential genes occurs at this one to $10^{4}$ frequency.

To verify the replacement of the chromosomal $r p s O$ gene in NB429, $\mathrm{Km}^{\mathrm{R}}$ recombinants were purified by patching on $\mathrm{LB}-\mathrm{Km}$ plates. The individual colonies were then resuspended in sterile water and $1 \mu \mathrm{L}$ used as a template for PCR in the same conditions as above with the following pair of primers flanking the $\operatorname{rps} O$ gene: CTTTGCGTAACGTACACTGGGATC and TCCAGTGAATTGCT GCCGTCAGCT. There was no rpsO sequence present in the cells.

\section{Construction of $\Delta r p s O \mathrm{NB} 497$ strain}

To make $\Delta r p s O$ E. coli mutant suitable for further studies, the rpsO<>kan knockout was P1 transduced (Miller 1972) from
NB429 to W3110 background. The resulting NB497 strain (W3110 rpsO<>kan) contained a precise and complete $r p s O$ reading frame deletion in the otherwise wild-type background. This was confirmed again by PCR analysis of the NB497 cells followed by two-dimensional electrophoretic analysis of the NB497 ribosomal proteins (see below).

\section{Preparation of ribosomes}

The $\Delta r p s O \mathrm{NB} 497$ and the control W3110 strains were grown at $37^{\circ} \mathrm{C}$ in $\mathrm{LB}$ medium until $\mathrm{A}_{590} \cong 0.8-1.0$. The cells were harvested by centrifugation $\left(10,000 \mathrm{~g}, 15 \mathrm{~min}\right.$, at $\left.4^{\circ} \mathrm{C}\right)$, washed with buffer $10 \mathrm{mM}$ Tris-HCl (pH 7.5), $20 \mathrm{mM} \mathrm{MgCl}_{2}, 200 \mathrm{mM} \mathrm{NH}_{4} \mathrm{Cl}, 3 \mathrm{mM}$ 2-mercaptoethanol, centrifuged again as above, and cell pellets stored at $-70^{\circ} \mathrm{C}$ until further use.

To obtain ribosomes, the cells were disrupted with $\mathrm{Al}_{2} \mathrm{O}_{3}$ in the above buffer (1:2:1 ratio) and the cell lysates were twice centrifuged $\left(30,000 \mathrm{~g}, 15 \mathrm{~min}, 4^{\circ} \mathrm{C}\right)$ to remove cell debris. The supernatants were loaded over a 30\% sucrose cushion made in buffer 10 $\mathrm{mM}$ Tris- $\mathrm{HCl}$ (pH 7.5), $10 \mathrm{mM} \mathrm{MgCl}_{2}, 200 \mathrm{mM} \mathrm{NH}_{4} \mathrm{Cl}, 3 \mathrm{mM}$ 2-mercaptoethanol, and centrifuged in a tabletop TL-100 ultracentrifuge (Beckman-Coulter) in a TLA-100.3 rotor at $380,000 \mathrm{~g}$ for $3 \mathrm{~h}$. The ribosome pellets were resuspended in the same buffer, but containing $100 \mathrm{mM} \mathrm{NH} \mathrm{NH}_{4} \mathrm{Cl}$, cleared by centrifugation $\left(15,000 \mathrm{~g}, 15 \mathrm{~min}, 4^{\circ} \mathrm{C}\right)$, frozen in $10 \%$ glycerol with liquid nitrogen and stored at $-70^{\circ} \mathrm{C}$.

Alternately after harvesting, equal O.D.s of cells were lyzed by addition of $4.0 \mathrm{~mL}$ chilled lysis/dissociation buffer (10 mM Tris$\mathrm{HCl}$ at $\mathrm{pH} 7.8,15 \mathrm{mM} \mathrm{MgCl} 2,1 \mathrm{mg} / \mathrm{mL}$ lysozyme) and frozen in a dry ice/ethanol bath. To finish cell lysis, cells were thawed in an ice water bath. Fifteen microliters $10 \%$ deoxycholate was added to each sample and the samples were centrifuged at $13,2000 \mathrm{rpm}$ for $20 \mathrm{~min}$ at $4^{\circ} \mathrm{C}$. Lysates were loaded onto a $10 \%-40 \%$ sucrose gradient containing $20 \mathrm{mM}$ Tris- $\mathrm{HCl}$ ( $\mathrm{pH} \mathrm{7.8),} 10.0 \mathrm{mM} \mathrm{MgCl}_{2}$, $100 \mathrm{mM} \mathrm{NH}_{4} \mathrm{Cl}$, and $2 \mathrm{mM} \mathrm{DTT}$. Gradients were centrifuged in an SW-41 rotor for $3.5 \mathrm{~h}$ at $35,000 \mathrm{rpm}$ at $4^{\circ} \mathrm{C}$. Ribosomes prepared in this manner were used for gradient analysis. $30 \mathrm{~S}$ and $50 \mathrm{~S}$ subunits were collected from such gradients and isolated as previously described (Moazed et al. 1986).

\section{Two-dimensional gel electrophoresis of ribosomal proteins}

Total ribosomal proteins were extracted from $2 \mathrm{mg}$ ribosomes using the acetic acid method (Siegmann and Thomas 1987). The ribosomes in the storage buffer were adjusted to $100 \mathrm{mM} \mathrm{MgCl}_{2}$ and stirred together with glacial acetic acid $(1: 2$ ratio $)$ at $0^{\circ} \mathrm{C}$ for $40 \mathrm{~min}$. The mixture was centrifuged $\left(15,000 \mathrm{~g}, 15 \mathrm{~min}, 4^{\circ} \mathrm{C}\right)$ to remove rRNAs and the proteins were precipitated overnight at $-20^{\circ} \mathrm{C}$ with 6 volumes of acetone. Proteins were dialyzed against the sample buffer and analyzed by two-dimensional electrophoresis using the acidic-acidic system IV (Madjar et al. 1979), followed by Coomassie G staining of gels.

\section{Isolation of rRNA for analysis of $5^{\prime}$ end processing}

Polysome gradients were run as described above for both W3110: parent and $\Delta r p s O$ : mutant grown at $24^{\circ} \mathrm{C}$. One-milliliter fractions were collected and RNA was extracted as previously described (Culver and Noller 2000). 


\section{Chemical modification and primer extension analysis}

Chemical modification, RNA extraction, and primer extension analysis was performed as previously described (Moazed et al. 1986; Culver and Noller 2000).

\section{Subunit association}

Subunit association assays were performed as previously described (Culver and Noller 1999). In this work, 30 pmol of 30 S subunits and $50 \mathrm{pmol}$ of $50 \mathrm{~S}$ subunits from each of the two different strains (W3110: parent and $\Delta$ rpsO: mutant) were used either in control or association assays as indicated in the figure legend. Sucrose gradient sedimentation analysis of subunit association was performed essentially as previously described (Culver and Noller 1999). For the experiments that are shown, the $\mathrm{MgCl}_{2}$ concentration in the association assays and accompanying gradients was $10 \mathrm{mM}$. Additional experiments with $\mathrm{MgCl}_{2}$ concentration of $20 \mathrm{mM}$ were also tried and yielded similar results to the lower concentration of $\mathrm{MgCl}_{2}$.

\section{ACKNOWLEDGMENTS}

We thank Georgy Gongadze for his advice on 2D electrophoresis and Nina Bubunenko for her help in the preparation of DNA oligonucleotides. We also thank Kristi Holmes for assistance with Figure $1 \mathrm{~B}$ and Laura Dutca and Kirthi Narayanaswamy for comments on the manuscript. A portion of this work was supported by a grant from the National Institutes of Health (GM62432) to G.M.C., by a grant from the Howard Hughes Medical Institute to M.B.G., and by a Trans NIH/FDA Intramural Biodefense Program Grant from NIAID (D.L.C.). M.B.G. was supported by the Russian Academy of Sciences and the Program for Molecular and Cellular Biology RAS.

This project has been funded in part with federal funds from the National Cancer Institute, National Institutes of Health, under contract N01-CO-12400. The content of this publication does not necessarily reflect the views or policies of the Department of Health and Human Services, nor does mention of trade names, commercial products, or organizations imply endorsement by the U.S. Government.

Received October 15, 2005; accepted March 16, 2006.

\section{REFERENCES}

Agalarov, S.C., Selivanova, O.M., Zheleznyakova, E.N., Zheleznaya, L.A., Matvienko, N.I., and Spirin, A.S. 1999. Independent in vitro assembly of all three major morphological parts of the 30 S ribosomal subunit of Thermus thermophilus. Eur. J. Biochem. 266: 533-537.

Agalarov, S.C., Sridhar Prasad, G., Funke, P.M., Stout, C.D., and Williamson, J.R. 2000. Structure of the S15,S6,S18-rRNA complex: Assembly of the 30 S ribosome central domain. Science 288: 107113.

Brodersen, D.E., Clemons Jr., W.M., Carter, A.P., Wimberly, B.T., and Ramakrishnan, V. 2002. Crystal structure of the 30 S ribosomal subunit from Thermus thermophilus: Structure of the proteins and their interactions with 16 S RNA. J. Mol. Biol. 316: 725-768.

Cannone, J.J., Subramanian, S., Schnare, M.N., Collett, J.R., D'Souza, L.M., Du, Y., Feng, B., Lin, N., Madabusi, L.V., Muller, K.M., et al. 2002. The comparative RNA Web (CRW):
An online database of comparative sequence and structure information for ribosomal, intron and other RNAs. BMC Bioinformatics 3: 2 .

Carson, M. 1997. Ribbons. Methods Enzymol. 277: 493-505.

Court, D.L., Sawitzke, J.A., and Thomason, L.C. 2002. Genetic engineering using homologous recombination. Annu. Rev. Genet. 36: 361-388.

Cukras, A.R. and Green, R. 2005. Multiple effects of S13 in modulating the strength of intersubunit interactions in the ribosome during translation. J. Mol. Biol. 349: 47-59.

Culver, G.M. and Noller, H.F. 1999. Efficient reconstitution of functional Escherichia coli 30 S ribosomal subunits from a complete set of recombinant small subunit ribosomal proteins. RNA 5: 832-843.

- 2000. Directed hydroxyl radical probing of RNA from iron(II) tethered to proteins in ribonucleoprotein complexes. Methods Enzymol. 318: 461-475.

Culver, G.M., Cate, J.H., Yusupova, G.Z., Yusopov, M.M., and Noller, H.F. 1999. Identification of an RNA-protein bridge spanning the ribosomal subunit interface. Science 285: 2133-2135.

Dammel, C.S. and Noller, H.F. 1993. A cold-sensitive mutation in $16 \mathrm{~S}$ rRNA provides evidence for helical switching in ribosome assembly. Genes \& Dev. 7: 660-670.

- 1995. Suppression of a cold-sensitive mutation in 16S rRNA by overexpression of a novel ribosome-binding factor, RbfA. Genes \& Dev. 9: 626-637.

Ferreira-Cerca, S., Poll, G., Gleizes, P.E., Tschochner, H., and Milkereit, P. 2005. Roles of eukaryotic ribosomal proteins in maturation and transport of pre-18S rRNA and ribosome function. Mol. Cell 20: 263-275.

Grondek, J. and Culver, G.M. 2004. Assembly of the 30S ribosomal subunit: Positioning ribosomal protein S13 in the S7 assembly branch. RNA 10: 1861-1866.

Guthrie, C., Nashimoto, H., and Nomura, M. 1969. Structure and function of $E$. coli ribosomes. VIII. Cold-sensitive mutants defective in ribosome assembly. Proc. Natl. Acad. Sci. 63: 384391.

Held, W.A., Mizushima, S., and Nomura, M. 1973. Reconstitution of Escherichia coli $30 \mathrm{~S}$ ribosomal subunits from purified molecular components. J. Biol. Chem. 218: 5720-5730.

Held, W.A., Ballou, B., Mizushima, S., and Nomura, M. 1974. Assembly mapping of $30 \mathrm{~S}$ ribosomal proteins from Escherichia coli. J. Biol. Chem. 249: 3103-3111.

Madjar, J.J., Michel, S., Cozzone, A.J., and Reboud, J.P. 1979. A method to identify individual proteins in four different twodimensional gel electrophoresis systems: Application to Escherichia coli ribosomal proteins. Anal. Biochem. 92: 174-182.

Miller, J.H. 1972. Experiments in molecular genetics. Cold Spring Harbor Laboratory, Cold Spring Harbor, New York.

Mizushima, S. and Nomura, M. 1970. Assembly mapping of 30 S ribosomal proteins in E. coli. Nature 226: 1214-1218.

Moazed, D., Stern, S., and Noller, H.F. 1986. Rapid chemical probing of conformations in $16 \mathrm{~S}$ ribosomal RNA and $30 \mathrm{~S}$ ribosomal subunits using primer extension. J. Mol. Biol. 187: 399-416.

Nomura, M., Mizushima, S., Ozaki, M., Traub, P., and Lowry, C.V. 1969. Structure and function of ribosomes and their molecular components. Cold Spring Harb. Symp. Quant. Biol. 34: 49-61.

Orr, J.W., Hagerman, P.J., and Williamson, J.R. 1998. Protein and $\mathrm{Mg}(2+)$-induced conformational changes in the S15 binding site of 16 S ribosomal RNA. J. Mol. Biol. 275: 453-464.

Powers, T. and Noller, H.F. 1995. Hydroxyl radical footprinting of ribosomal proteins on 16S rRNA. RNA 1: 194-209.

Recht, M.I. and Williamson, J.R. 2001. Central domain assembly: Thermodynamics and kinetics of S6 and S18 binding to an S15RNA complex. J. Mol. Biol. 313: 35-48.

Schuwirth, B.S., Borovinskaya, M.A., Hau, C.W., Zhang, W., VilaSanjurjo, A., Holton, J.M., and Cate, J.H. 2005. Structures of the bacterial ribosome at 3.5 A resolution. Science 310: 827-834. 
Siegmann, M. and Thomas, G. 1987. Separation of multiple phosphorylated forms of $40 \mathrm{~S}$ ribosomal protein S6 by two-dimensional polyacrylamide gel electrophoresis. Methods Enzymol. 146: 362369.

Stern, S., Powers, T., Changchien, L.M., and Noller, H.F. 1988. Interaction of ribosomal proteins S5, S6, S11, S12, S18 and S21 with 16 S rRNA. J. Mol. Biol. 201: 683-695.

Svensson, P., Changchien, L.M., Craven, G.R., and Noller, H.F. 1988. Interaction of ribosomal proteins, S6, S8, S15 and S18 with the central domain of 16 S ribosomal RNA. J. Mol. Biol. 200: 301308.

Thomason, L.C., Bubunenko, M., Constantino, N., Wilson, H., Oppenheim, A., Datta, S., and Court, D.L. 2005a. Recombineering: Genetic engineering in bacteria using homologous recombination. In Current Protocols in Molecular Biology., pp. 1.16. 11-21. Wiley., Hoboken, NJ.

Thomason, L.C., Myers, R.S., Oppenheim, A., Constantino, N., Sawitzke, J.A., Datta, S., Bubunenko, M. and Court, D.L. 2005b. Recombineering in prokaryotes. In Phages: Their role in bacterial pathogenesis and biotechnology (eds. M.K. Waldor and D.I.
Friedmanm, and S.L. Adhya), pp. 383-399. ASM Press, Herndon, VA.

Traub, P., Hosokawa, K., Craven, G.R., and Nomura, M. 1967. Structure and function of E. coli ribosomes, IV. Isolation and characterization of functionally active ribosomal proteins. Proc. Natl. Acad. Sci. 58: 2431-2436.

Wimberly, B.T., Brodersen, D.E., Clemons, W.M.J., MorganWarren, R.J., Carter, A.P., Vonrhein, C., Hartsch, T., and Ramakrishnan, V. 2000. Structure of the 30 S ribosomal subunit. Nature 407: 327-339.

Yu, D., Ellis, H.M., Lee, E.C., Jenkins, N.A., Copeland, N.G., and Court, D.L. 2000. An efficient recombination system for chromosome engineering in Escherichia coli. Proc. Natl. Acad. Sci. 97: 5978-5983.

Yusupov, M.M., Yusupova, G.Z., Baucom, A., Lieberman, K., Earnest, T.N., Cate, J.H., and Noller, H.F. 2001. Crystal structure of the ribosome at 5.5 A resolution. Science 292: 883-896.

Zengel, J.M. and Lindahl, L. 1994. Diverse mechanisms for regulating ribosomal protein synthesis in Escherichia coli. Prog. Nucleic Acid Res. Mol. Biol. 47: 331-370. 

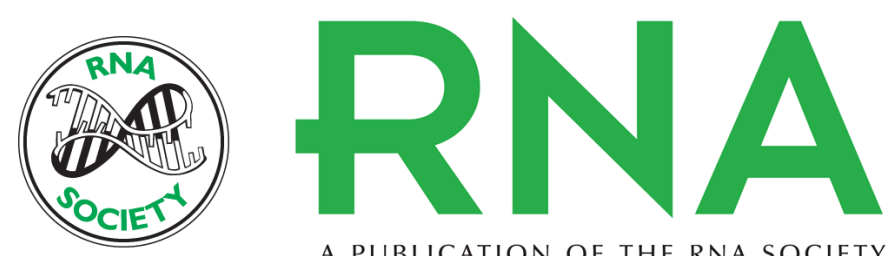

A PUBLICATION OF THE RNA SOCIETY

\section{$30 S$ ribosomal subunits can be assembled in vivo without primary binding ribosomal protein $\mathrm{S} 15$}

Mikhail Bubunenko, Alexey Korepanov, Donald L. Court, et al.

RNA 2006 12: 1229-1239

References This article cites 33 articles, 13 of which can be accessed free at:

http://rnajournal.cshlp.org/content/12/7/1229.full.html\#ref-list-1

License

Email Alerting Receive free email alerts when new articles cite this article - sign up in the box at the Service top right corner of the article or click here.

To subscribe to RNA go to:

http://rnajournal.cshlp.org/subscriptions 